\title{
Why should we respect the privacy of donors of biological material?
}

Medicine, Health Care and

Philosophy

A European Journal

ISSN 1386-7423

Volume 14

Number 1

Med Health Care and Philos

(2010) 14:43-52

DOI 10.1007/s11019-010-9292-

$\mathrm{x}$

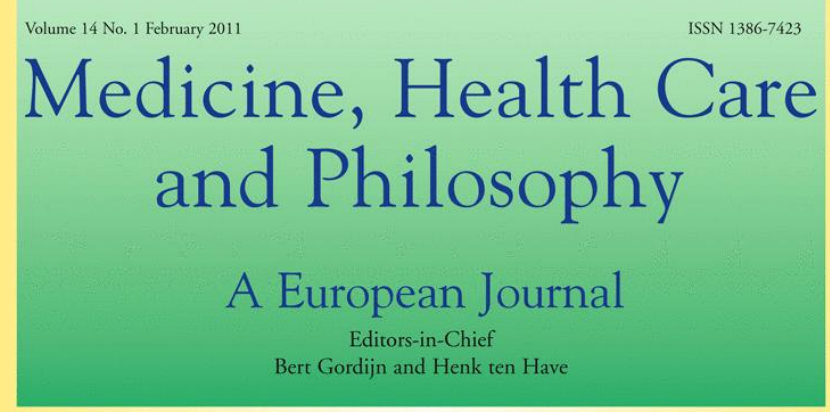

Editorial

HENK TEN HAVE and BERT GORDIJN / Travelling bioethics

Scientific Contributions

JORIS GIELEN, SUSHMA BHATNAGAR, SEEMA MISHRA, ARVIND K. CHATURVEDI. HARMALA GUPTA, AMBIKA RAJVANSHI, STEF VAN DEN BRANDEN and BERT BROECKAERT / Can curative or life-sustaining treatment be withheld of withdrawn? The opinions and views of Indian palliative-care nurses and physicians ERIK MALMQVIST, GERT HELGESSON, JOHANNES LEHTINEN, KARI NATUNEN and MATTI LEHTINEN/The ethics of implementing human papillomavirus vaccination in developed countries

STEF VAN DEN BRANDEN and BERT BROECKAERT / Living in the hands of God. English Sunni e-fatwas on (non-)voluntary euthanasia and assisted suicide

TORBJÖRN TÄNNSJÖ / Why should we respect the privacy of donors of biological material? HELGA GOTTFREĐSDÓTTIR and VILHJÁLMUR ÁRNASON / Bioethical concepts in theory and practice: an exploratory study of prenatal screening in Iceland MARIA C. STUIFBERGEN and JOHANNES J. M. VAN DELDEN / Filial obligations to elderly
5-18

Official Journal of the European Society for Philosophy of Medicine and Health Care.

\section{亚 Springer}


Your article is protected by copyright and all rights are held exclusively by Springer Science+Business Media B.V.. This e-offprint is for personal use only and shall not be selfarchived in electronic repositories. If you wish to self-archive your work, please use the accepted author's version for posting to your own website or your institution's repository. You may further deposit the accepted author's version on a funder's repository at a funder's request, provided it is not made publicly available until 12 months after publication. 


\title{
Why should we respect the privacy of donors of biological material?
}

\author{
Torbjörn Tännsjö
}

Published online: 21 October 2010

(C) Springer Science+Business Media B.V. 2010

\begin{abstract}
Why should we respect the privacy of donors of biological material? The question is answered in the present article in general philosophical terms from the point of view of an ethics of honour, a libertarian theory of rights, a view of respect for privacy based on the idea that autonomy is of value in itself, and utilitarianism respectively. For different reasons the ethics of honour and the idea of the value of autonomy are set to one side. It surfaces that the moral rights theory and utilitarianism present conflicting answers to the question. The main thrust of the argument is that there is no way of finding an overlapping consensus, so politicians have to take decisions that are bound to be controversial in that they can be questioned on reasonable philosophical grounds.
\end{abstract}

Keywords Biobanks - Privacy · Honour - Rights ·

Autonomy $\cdot$ Utilitarianism

\section{Introduction}

There is much concern and even dismay in the medical world about all the rules surrounding 'bio-banking', i.e. the

This article has been written in connection with the European research project TissEU. Tiss.EU stands for 'Evaluation of Legislation and Related Guidelines on the Procurement, Storage and Transfer of Human Tissues and Cells in the European Union-an EvidenceBased Impact Analysis.' The project has been funded by the European Commission as part of the 7th Framework Programme. I thank all the participants in the project for valuable comments on my paper, which was presented in a preliminary form at a conference with the project in Stockholm on 25 March 2010.

T. Tännsjö ( ()

Department of Philosophy, Stockholm University,

10691 Stockholm, Sweden

e-mail: torbjorn.tannsjo@philosophy.su.se storing of biological material not only for therapeutic but also for medical scientific purposes. It is though that complicated rules about consent and the right to withdraw material render medical science difficult, expensive and hence unnecessarily slow. The situation may appear even worse when it is realised that all this regulation seems to be based on a simple logical mistake. The idea that the donor of biological material should have a right at will to redraw material is the result of misuse of words, and of the word 'bank' in particular. It is obvious that you should be allowed to withdraw your savings from a bank. However, in the present context, 'bank' is a misnomer. You don't put your biological material in a bio-bank in any way similar to when you put your savings in an ordinary bank. You give up your biological material once you accept to 'put' it in a bio-bank. And, indeed, when you 'withdraw' your biological material, this does not always-ever, as a matter of fact-mean that you get it back. What happens when you withdraw your consent is that your biological material gets 'anonymized' in some manner (a 'key' between you and the material stemming from you is destroyed, or something of the sort). You would hardly accept that kind of withdrawal of your savings from an ordinary bank!

Furthermore, the idea that strict regulation is needed has to do with what seems to be a misplaced analogy. I think of the analogy with medical experiments on people. Such experiments pose a constant threat to the health and wellbeing of the research subject, and it is hence reasonable to require that the research subject must indeed give an explicit and informed consent to the research on her, and that she should be able at any time to withdraw her consent. The storing of biological material in a bio-bank poses no comparable threat, it has been claimed.

To this is may be retorted, however, that the use of biological material in bio-banks, unless strictly regulated, 
means a threat to the privacy of the donors. Is that a good reason to stick to a complicated and costly system? This depends on what it means to have a right to privacy, of course, and on the strength and content of this right. This is the theme of the present article. The idea is not to develop specific regulations but to discuss, in general terms, the philosophical issues raised by the question.

It is commonly thought, then, that the privacy of donors of material to bio-banks should be protected. Why should it be protected? In what way? This is a problem in applied ethics. I will address it in the present article. I will transpire that what kind of protection is reasonable is a controversial issue. When we assess it from different moral points of view we end up with different notions of privacy and different answers to the question. Then it is of interest to see whether there is any possibility of reaching an overlapping consensus, a conclusion that can be defended from the point of view of very different moral outlooks. Is there such a possibility? In the present context, there seems to be no such possibility. This is the main thesis of this article. How, then, should society react? At the end of this article I raise and answer this question. First a few words about applied ethics in general.

\section{Applied ethics}

In applied (or practical) ethics, we seek answers to practical questions, about what to do. These questions are as varied as human life. They range from individual questions (what ought I to do with my life?) to very general political questions (ought we to abolish capital punishment?). They include also, as we shall see, problems raised by thought experiments. The reasonable way of answering such questions is as follows. We find a moral principle, which is applicable to the case at hand, we make an account of the relevant non-moral facts, and we deduce the answer to our question:

\section{(1) MORAL PRINCIPLE \\ (2) RELEVANT NON-MORAL FACTS \\ (3) PRACTICAL CONCLUSION}

By so doing, if we hit upon a true moral principle, we get moral guidance; we learn what to do. Moreover, since the argument has the structure of an ordinary covering-law explanation in science, where the practical conclusion, to the effect that this is what ought to be done, plays the role of our explanandum, and the moral principle the role of the statement of a law of nature, and the statement of the nonmoral relevant facts the role of our initial conditions (together they constitute our explanans), we also learn why we ought to do what we ought to do. It is assumed here that the moral principle is essential to the deduction of the practical conclusion and that it has a kind of necessity built into it, quite similar to the one built into a law of nature. We can project it onto unknown cases; it supports counterfactuals, and so forth. The principle specifies right- and wrong-making (and hence also ought-making) characteristics.

The application of the model is sometimes quite straightforward. If we apply a simple deontological principle, such as the one that it is wrong intentionally to kill an innocent human being, to a case where an innocent human being was killed intentionally, we can deduce the conclusion that this was wrong. This normative fact, then, is our explanandum. However, other principles, such as utilitarianism, are more demanding of non-moral factual information. Here we need to have recourse to various different auxiliary, 'bridging', hypotheses, and even methods of decision-making motivated on utilitarian grounds, and so forth, in order to reach a tentative conclusion about a particular case.

These are two obvious uses of the model; it can give us moral guidance and moral understanding. But it can also be put to a more mundane use. In many discussions about controversial issues, there is little understanding of the principled aspects of the issues. By putting the model to use, and by tentatively trying out various different putative moral principles, which may seem plausible to different people involved in the controversy, we can shed new light on it. At least these six possible outcomes of such a study are useful to keep apart.

(1) Practical disagreement based on fundamental moral disagreement. We can learn that the reason that people disagree, or should disagree, is that the different principles, to which they adhere, yield different conclusions, ones the relevant non-moral facts (relevant to each one of the principles involved in the controversy) are on the table.

(2) Practical agreement based on an overlapping consensus. We can learn that even if people disagree on basic principled moral questions, they should agree on the practical question at hand, since each principle, given its relevant non-moral facts, yields the same practical conclusion.

(3) Practical disagreement based on non-moral factual disagreement. We can learn that the disagreement that surfaces in the discussion must depend, not on different principled moral stances (since upon closer inspection those involved in the controversy agree about these); the disagreement, if it is recalcitrant, can be traced to different beliefs about the relevant nonmoral facts.

(4) Practical disagreement based on logical mistakes or the use of different systems of logic. Two persons 
who agree about moral principles and relevant nonmoral facts may yet disagree; at least one of them may have made a logical mistake, or they may be relying on different systems of logic. Even in logic there is room for some reasonable disagreement.

(5) Practical disagreement which is merely verbal; it is possible that the parties speak at cross-purposes. They use the same moral terms but use them with different meanings.

(6) Complete practical agreement based on agreement about basic moral principles, all the relevant facts, the same understanding of rules of logic, correct reasoning, and a common understanding of the terminology used.

All this is important as such, but there is an even more important lesson to be learnt from applied ethics. When we infer the answer to the practical question at hand it is crucial that our inference is not only valid but sound. We need to rely on both a true moral principle and a correct account of the non-moral relevant facts. However, it is not possible to know, without applying them to real and hypothetical cases, which moral principles are true and which are false. Applied ethics, however, can help us to justified beliefs about moral principles. But then we must move, not top down as we do when we derive our conclusion about the practical case, but bottom up, from the conclusion to the premises. If we hold a strong, independent and considered moral intuition about how the practical question should be answered, then a principle that explains the content of this intuition gains some evidential support. And the principle that gives the best explanation of the content of our moral intuition gets inductive support by this content (we make an inference to the best explanation). So applied ethics is a tool we need to resort to, if we want to improve our general and principled moral understanding. ${ }^{1}$

Here I will focus on the more mundane use of the model, however. I want to find out what kind of conclusion we can draw from various different moral outlooks for some specific questions about bio-banks, and I am interested in particular to find out whether there is room for any overlapping consensus. But in order to find this out we must be more specific about the questions we want to address.

\section{Controversial questions in relation to bio-banks}

In the present context I wan to discuss four different questions; they all relate to the question what sort of

\footnotetext{
${ }^{1}$ In this overview of possibilities I rely on my own forthcoming 'Applied Ethics. A Defence'. I there defend the use of the method. In the present context I just use it
}

consent should be sought before biological material is stored in a bio-bank, for non-therapeutic use. I think here of both scientific and forensic use:

(1) Broad or narrow consent. Need we be specific when we ask the donor for consent, or is it sufficient for us to ask for a broad consent, i.e. consent to all possible future use? Here I also want to discuss the question whether the donor should have a right to withdraw her consent.

(2) Implicit or explicit consent. Is it necessary to ask the donor for consent, or, is it perhaps sufficient that there is a possibility for the donor to opt out of the system if she wants to, where it is assumed (presumed) that everyone who does not say otherwise does consent?

(3) Forensic use. Should biological material be used for forensic use? Could an already established bio-bank be used for forensic purposes? Should special banks be established for this purpose? Would it be objectionable to construct a bio-bank, to be used for forensic purposes, where everyone had to participate (donate)? And, finally,

(4) Spare genetic material. What are we to say about the use of spare genetic material, which has been left behind by a 'donor'? Is it morally unobjectionable to send it to a laboratory for genetic analysis, if we happen go get hold of it? Is it, for example, acceptable if the hairdresser uses material from her customers to this effect? May the hairdresser send hair from a client to a genetic laboratory, have it diagnosed, and then have the result published?

These are the four cases I will use as examples in my discussion. I will try out four different moral perspectives, in order to see what kind of implications they have for my cases. These moral positions are an ethics of honour, a libertarian moral rights theory, the idea that autonomy is of value in itself, and, finally, utilitarianism. I have selected them for different reasons. The ethics of honour seems to have had a strong influence, at least on Western European thought. I discuss it because of its real impact on our thinking, not because of its inherent philosophical plausibility. Utilitarianism and the ethics of rights are both attractive moral views but, alas, lead to conflicting verdicts in the present context. That means that it is of outmost importance to confront them. Finally, the idea that our defence of privacy should be based on the idea that autonomy is assessed because it seems to be taken for granted in many discussions about bio-banks. However, as I will try to show, it is less apt to do this work than what is usually assumed.

Why only these four views? Why not examine for example ethical egoism, contractualism, virtue ethics, or an 
ethics of care $?^{2}$ This is a matter of space, mainly. Moreover, the ones I have chosen for my case study are sufficient for the conclusion that no compromise in the area is possible. Cleaver people with different moral outlooks are bound to disagree on the issue at hand.

\section{An ethics of honour}

The first moral outlook I want to consider is a bit surprisingly, an ethics of honour. We do not meet with this kind of theory in elementary courses of normative ethics. And yet, this kind of moral outlook seems to have a strong influence on our thoughts about privacy in general, at least in continental Europe. That's why it should be taken seriously - at least in an attempt to understand our cherished views on privacy. Typical of an ethics of honour is the assumption that certain actions are required of an agent, in certain situations, if he wants to protect his honour. If you fail to answer appropriately to a challenge to your honour, you feel shame.

Shame is a crucial notion in any ethics of honour, then, while the notion of guilt is alien. How do you distinguish these notions? This is a difficult philosophical problem, but phenomenologically speaking, everyone knows. When you feel guilt you want to make amends, to correct the harm. When you feel shame, you want to sink through the floor.

According to the legal scholar James Q. Whitman, Continental European tradition in regard to privacy, is moulded by an old tradition of honour. ${ }^{3}$ There used to be a time when the duelling classes, and the duelling classes only, were protected by this morality. Since then, however, a process of levelling up has taken place. Now everyone enjoys the kind of privilege that in those days only the nobility did. And the crucial aspect of this morality is the idea that everyone should control the public image of herself; when something you do not want to be disclosed about yourself is disclosed about yourself, this is an offence to your honour:

Continental privacy protections are, at their core, a form of protection of a right to respect and personal dignity. The core continental privacy rights are rights to one's image, name, and reputation, and what Germans call the right to informational self-determination - the right to control the sorts of information disclosed about oneself ... They are all rights to

\footnotetext{
${ }^{2}$ In my book, Understanding Ethics 2nd ed. (Edinburgh: Edinburgh UP/Columbia UP, 2009) I discuss these views at length. But that is a book, not a brief article for a philosophical journal.

${ }^{3}$ See his 'The Two Western Cultures of Privacy. Dignity Versus Liberty', The Yale Law Journal, Vol. 113, 2004 from which I quote.
}

control your public image-rights guarantee that people see you the way you want to be seen. (p. 1161)

This observation makes sense of actual legislation, but this does not mean that here we are presented with a plausible moral stance. Are we?

Certainly, an ethics of honor of this kind, is not in serious competition with moral rights theories, deontology, and utilitarianism, as a suggestion about what is the final truth in morality. An ethics of honour must be seen as a social construction, where the answer to the questions what is and what is not a challenge to your honour is constituted by social conventions. And yet, it might very well be that, as a matter of fact, people care about their reputation (honour) in the way here indicated. In that case, it might be of importance to see to it that the requirements by such a morality are met. So it is of interest to what the implications are from this moral outlook for the questions here posed.

First of all, if the matter is assessed from the point of view of this kind of an ethics of honour, it seems clear that the storing of biological materials in bio-banks is not objectionable as such. If the banks are used in a professional manner, then no information about the donors will be disclosed, so there is no threat there in the first place.

The donor may well want to be certain that the bank is handled in an appropriate manner. This renders a system where consent is thought reasonable. However, it is difficult to see why the consent could not be both wide and merely presumed, allowing for the sceptics to stay outside the bank. Any need for the right to withdraw material for the bank is not really necessary. It is hard to think of any use of the material you have donated that may come to threaten your public reputation. No information at all about you is supposed to be disclosed to the public; would that happen, legal sanctions could be taken against the biobank.

What are we to say about the storing of biological material for forensic use? Would it be objectionable, from the point of view of an ethics of honour, protecting our right to our own public image, if society required of every citizen that she donated some biological material for such a bio-bank, allowing the police, at a crime-scene, to mach a biological sample with data in the bio-bank? I see no problem with this, from the point of view of the moral outlook here put to scrutiny. This would enhance our security in society in relation to the police, and it would allow people, who are otherwise accused of crimes they have not committed, to regain their good name and reputation.

Finally, what are we to say about the use of spare genetic material for involuntary diagnosis? The answer to this question is obvious. This is a horrific possibility, if we 
want every person to be in control of her public image. It is hard to see how one should through legislation render such use of biological material impossible, but, according to the ethics of honour, no effort should be saved in an attempt to do so.

\section{A libertarian moral rights theory}

The idea I want to discuss here is a libertarian theory of rights in the tradition from John Locke and Robert Nozick, based on moral self-ownership. I focus on this version of the moral rights tradition for two reasons. First of all, I find this version of the view highly attractive. Secondly, it presents us with a startling contrast to the other views I discuss, in particular to utilitarianism.

The crucial idea in this version of the moral rights view is that everyone owns herself and this means that she is allowed to do as she sees fit with herself, as long as this does not mean a violation of the corresponding right of anyone else. These rights are negative rights. In addition to self-ownership there is an idea that it is possible also to gain a right to property. This is a controversial aspect of the theory, but in the present context I will only assume that we can gain property right to 'private' things, such as personal belongings, your home, and the like. I will not discuss other kinds of putative moral ownership and hence I will not discuss various different interpretations of Locke's proviso, supposed to govern the original acquisition of property.

The American philosopher Judith Jarvis Thomson does not accept the radical version of the moral rights theory here described, but she does defend a moral rights theory, she has famously applied it to the problem of our putative right to privacy, and in the present context the differences between her version of the theory and the traditional, hard core version, do not matter. Hence I will discuss her version of the theory in her application of it to the problem of privacy. ${ }^{4}$ After all, hers is the most quoted and also the best defence of a right to privacy that has been produced in this moral tradition. So it is a good idea, in the present context, to consider it rather than the kind of loose talk about a right to privacy that we often meet with in applied discussions about bio-banking.

Thomson's point of view is scepticism with regard to our putative right to privacy:

Perhaps the most striking thing about the right to privacy is that nobody seems to have any very clear idea what it is. ('The Right to Privacy', s. 295)

\footnotetext{
${ }^{4}$ I quote from her 'The Right to Privacy', Philosophy and Public Affairs, Vol. 4, 1975, pp. 295-314.
}

Yet, she finds a way of making sense of it. It is not, she claims, a right in its own right, but rather the result of various different property rights:

... the right to privacy is itself a cluster of rights, and that it is not a distinct cluster of rights but itself intersects with the cluster of rights which the right over the person consists in and also with the cluster of rights which owning property consists in. (Ibid., s. 306)

She explains this with reference to a man who owns a pornographic picture and keeps out of sight of everyone:

Does owning a picture also include having the negative right that others shall not look at it? I think it does. If our man's picture is good pornography, it would be pretty mingy of him to keep it permanently hidden so that nobody but him shall ever see it-a nicer person would let his friends have a look at it too. But he is within his rights to hide it. (Ibid., s. 299)

If he keeps the picture in a wall-safe, he has the right that no one looks at it. If someone constructs an apparatus that allows him to see it, through the thick wall, then this means a violation of the man's right to privacy.

How is this possible? It is possible, according to Thomson, since owning something means, not only that no one destroys it, takes it from you without your consent, but also that no one looks at it, smells it, and the like, unless you give your permission. The same is true, of course, of our own body:

I suppose you could not very well sell your left knee. But that isn't because it isn't ours to sell-some women used to sell their hair, and some people nowadays sell their blood-but only because who'd buy a used knee; but you've a right to damage yours, and certainly nobody else has-its being your left knee includes your having the right that nobody else but you shall damage it. And, as I think, it also includes your having the right that nobody else shall touch it or look at it. (p. 303)

Let us accept all this for the sake of the argument. Remember that it does also involve a possibility that you waive your right. You may permit someone to watch your picture or you may allow someone to touch your left knee:

In short you might waive your right that your left knee not be touched or looked at. But that is what doing these things would be: waiving a right. (s. 303)

When have I waived my right not to be listened to? If a quarrel loudly with my spouse before an open window, I have waived it, according to Thomson. There is some 
vagueness here, but we need not go into this problem in the present context. What is clear is that we can waive our right not to be seen or listened to, and so forth, even nonvoluntarily. And once you have left some property behind, in a manner signalling that it is no longer yours, everyone else may do as he sees fit with it. This means that we have no right, in this tradition, to control the public image of ourselves:

Again, suppose I find out by entirely legitimate means (e.g. from a third party who breaks no confidence in telling me) that you keep a pornographic picture in your wall-safe; and suppose that, though I know it will cause you distress, I print the information in a box on the front page of my newspaper, thinking it newsworthy: Professor Jones of State U. Keeps Pornographic Picture in Wall-Safe! Do I violate your right to privacy? I ... am inclined to think not. (309)

Where does such a view of a right to privacy leave us in relation to bio-banks? First of all, the use of bio-banks is no problem. If people accept to donate, or even sell biological material to bio-banks, they should be allowed to do so. It is crucial that consent based on correct information is obtained from the donor (or seller) before the material is stored, of course, but once an agreement has been reached, its terms must be honoured. If there is a right provided for the donor or seller to withdraw the material, such a right exists. But if no such right has been negotiated, this is no problem; then, simply, it does not exist. What we meet with here is an ordinary economic transaction in no ways different from the ones we often make in our lives, such as when we give away or sell our house or our car. A person who has sold his house has no right to give instructions to the new owner about the use of it. In a similar vein, he who has given away or sold biological samples to a bio-bank should not complain when they are put to a use he doesn't like.

There is of course no room for presumed consent in this tradition. Unless an explicit, and even written, consent has been obtained, there is no room for the storing of biological material from a person. Here standard contract theory applies.

What are we to say of a forensic bio-bank, to which everyone has to contribute biological material, in order to facilitate the search for criminals? There is no room for such a bio-bank in this moral tradition. The biological material can only be obtained if people, who are not suspected of any criminal action in particular, agree to donate or sell it. The idea that we should all have an obligation to contribute is anathema to the moral rights tradition.

Finally, what are we to say about spare genetic material? The answer to this question, it seems to me, is unexpected but rather obvious. Just as there exists a right to publish private and embarrassing information about a person, without consent from this person, if it has been obtained in a legitimate way, it is permitted to use spare genetic material for diagnostic purposes. It is furthermore permitted to publish the results of such an analysis, or to use them for any purpose, as long is this does not mean that any rights of anyone are being violated. The crucial thing is that the material has really been given up and that the moral property right in it has been waived. Typically, this is what happens when you have your hair cut by your barber and then walks away from him-unless you have arranged differently, of course, when you bought his services.

\section{The value of autonomy}

It is commonly thought that our right to privacy somehow must be founded on the value of autonomy. In order to safeguard autonomy, we must respect privacy. Consent is 'predicated on autonomy', is a common saying. ${ }^{5}$

What does it mean to be autonomous? It means that you are capable of leading an autonomous life, i.e. you are capable of making autonomous decisions. What does that mean? When do you exhibit the relevant kind of competence?

A person is competent of leading an autonomous life, I submit, if she is capable of doing what she does because this is what she decides to do, and she decides to do it because this is what she wants to do. Some qualifications are necessary, however.

First of all, the person must conceive of him as an agent. If he does not, if he sees his actions as governed by someone else, by the fate, by powers outside his own influence, he is not competent. Hence, if you are in the grips of a paranoid psychosis, you are not competent.

On the other hand, he must not conceive of himself as omnipotent. He must realise that the outcome of his actions depend, not only on his own choice, but on the state of affairs in the world, the actions of other agents, and so forth.

Moreover, he must not only be able to realise that the outcome of his actions depend on a variety of circumstances; he must be able to hold some view about the likelihood of various different outcomes of his actions, and he must hold some view about how desirable these outcomes are. He must then be able to apply some method of decision-making, weighing together probabilities and the desirability of the various different possible outcomes, and recommending one of the alternatives facing him. Or, if

\footnotetext{
${ }^{5}$ I'googled' the phrase and found more than 100,000 instances.
} 
there is a draw, it can allow him to just pick one of the best alternatives. $^{6}$

This is not enough, however, he must also be capable of making effective decisions. This means that a person, who decides not to drink, but still drinks, when there is an occasion for it, is not competent. At least he is not competent in relation to alcohol. He may of course yet be capable of making other decisions, such as the decision to accept or refuse a certain suggested therapy for his drinking problem.

Finally, he must be able to revise his views about probabilities and values, given new evidence or different life experiences. Hence, a person who believes that the medication he is given to cure his psychosis will poison him is not capable; at least, he is not capable if this belief has a compulsive character and if it is immune to contrary evidence. The person who believes that he will go to hell if he accepts a blood transfusion may well be competent, on the other hand, only provided this religious belief can in principle be changed. I suppose this condition is often fulfilled, even for religious people who, as a matter of fact, never change their views. ${ }^{7}$

It is sometimes thought that if a person is competent of leading an autonomous life, his decisions with regard to himself should be respected. I think this idea is basically sound, but it is of no relevance in the present context. Here we must focus instead on the idea that autonomy is something valuable. If autonomy is valuable it is not farfetched to think that there are situations where we have to coerce people in their own best interest-in order to protect or enhance their autonomy!

But if autonomy is thought to be valuable, one might think that this means that, in some situations, the privacy of people should be protected. Unless it is protected, they are not capable of leading autonomous lives.

Even if this is a popular line of thought, it is a line of thought of which it is extremely difficult to make good sense. Think of the concrete questions we have posed in relation to bio-banks. What are we to say about them, if we want to protect the autonomy of the donors of biological material?

Suppose a person donates genetic material, is promised absolute secrecy about the results of any kind of diagnosis of it, but finds that these results are indeed disclosed to the public at large? This person has a right to be angry, of course (and if he believes in the ethics of honour earlier discussed it is certain that he is), and it is clear that he has

\footnotetext{
${ }^{6}$ For an illumination account of the distinction between picking and choosing, see Ullmann-Margalit E. and Morgenbesser, S. (1977), 'Picking and Choosing', Social Research, 44, pp. 757-85.

${ }^{7}$ I here rely on my Coercive Care (London and New York: Routledge, 1999). In the book I elaborate on all the conditions. Here it must suffice with a rough statement of them.
}

been taken advantage of. But in what way has his autonomy been put in jeopardy? Is there any way of showing that the disclosure of the private information about him renders it difficult for him to live an autonomous life?

Perhaps his autonomy is threatened if he is paralysed by the knowledge that everyone knows things about him he doesn't want to be known. However, this is very extreme reaction and probably a rare one. And note that, even if in some rare cases a person's autonomy is threatened by such a use, there are probably cases where it is enhanced by the same kind of use. When you learn that you are taken advantage of, this may trigger your interest in leading your own life.

The same thing is true of an obligatory forensic biobank, would such a thing be created. If this person believes in a theory of rights, say, she will be vary angry, if she is forced to contribute material to this bank. But this would in no way render it impossible for this person to take autonomous decisions. In rare cases it would perhaps threaten the autonomy of a person when this happens to her, in other cases it would rather help her to develop her capacity for autonomous decision-making.

Finally, the use of spare genetic material is no different from the misuse of material in a bio-bank. It may cause rage when it takes place, but as such it does not threaten the capacity of the donor to lead an autonomous, rather than a heteronymous, life.

This does not mean that there is no room for the idea that a right to privacy should be based on the idea that autonomy is of value in itself. It might be the case that, unless the individual is granted at least some space, where she is left to herself, she cannot think freely, she cannot contemplate forbidden but important ideas, and so forth. However, as has been famously noted by Sir Isaiah Berlin, what is needed then is merely a narrow inner citadel. He makes his point with reference to Immanuel Kant:

Kant's free man needs no public recognition for his inner freedom. If he is treated as a means to some external purpose, that is a wrong act on the part of his exploiters, but his own 'noumenal' status is untouched, and he is fully free, and fully a man, however he may be treated. ('Two concepts of liberty', in Four Essays on Liberty, p. 156)

It seems that the idea that privacy should be founded on respect for the value of autonomy is a non-starter, not as such, but when applied to bio-banking.

\section{Utilitarianism}

Utilitarianism is the idea that we ought to maximise utility. In the present context I will discuss it in its classical, 
hedonistic version, according to which utility is understood as happiness. The idea is that each being who is capable of feeling pleasure (or pain) and who is, at each moment, at some hedonistic level, has (equal) moral status. If we want to assess how well a life has gone, we just sum the happiness in it. Pain is measured on the same scale, where it is represented with negative numbers. The zero is represented by a situation where you are unconscious. If, hedonistically speaking, your situation is preferable to a state of unconsciousness, it is positive, if it is the other way round, it is negative. We also sum between lives. And an action is right if and only if it maximises the sum total of happiness in the world.

The theory easily generalises to other kinds of utilitarianism in a discussion of bio-banks. Hence, it is not problematic to focus in the discussion on the simple hedonistic version of it.

A standard objection to utilitarianism in general, and also to the simplest version of it, hedonistic utilitarianism, is that it is not applicable in real life. It is so demanding of factual non-moral information that we can never apply it with any confidence and deduce a practical recommendation. It is of no use, when we want to do applied ethics, it has been held.

All utilitarians accept this objection. If utilitarianism is true then, probably, we hardly ever act rightly, and even if in rare cases we do, this is something we cannot know.

The standard answer to this objection, then, is not to deny its truth, but to deny that it is at all relevant in a discussion in normative ethics. Who said that the moral truth in practical cases should be easily accessible? Does it not indeed speak against the plausibility of a moral view if it renders our moral life simple? Secondly, and more important in the present context, utilitarians tend to argue that we should still try to find some method of practical moral decision-making which is informed by the belief in utilitarianism and which is applicable in practical life.

The standard idea about such a method is that unless, for some reason, doing so is counterproductive, we should try to maximise the expected sum-total of happiness. This means that we go on our-informed-ideas about probabilities and values and attempt to maximise a weighed sum of probabilities and values. We do this in the hope that, if consistently we do it, we will, in the long run, reach better results than we would do, if instead we were to use any other method. ${ }^{8}$

\footnotetext{
${ }^{8}$ The distinction between criteria of rightness and methods of decision-making was first clearly made in Bales, E., 'Act-Utilitarianism: Account of Right-Making Characteristics or Decision-Making Procedure?' American Philosophical Quarterly Vol. VII, 1971, pp. 256-65. In one form or another all adherents of act-utilitarianism today accept it.
}

What is a utilitarian to say of bio-banks? Because of the complexity of the factual matters I will only speculate rather briefly here. It is more important to indicate what sorts of considerations are relevant, than to really settle the issue (an impossible task in this restricted space). One might think that, since utilitarianism is a version of the idea that the end justifies the means, there should be no need even to ask donors for consent. Bio-banks are useful, so why not just use biological material from patients and do research on it?

However, a standard utilitarian argument why we should ask for consent is that, if medical science is important, it is also important to guarantee that there is public support for it. And a system where biological material is used without consent might engender suspicions about medical research, suspicions that may at the end of the day render it very difficult to pursue such research. Furthermore, if there is distrust among the public at large, then here will also be unhappiness. So we ought to seek consent from the donors. Furthermore, since, as a matter of fact, most people are prepared to give consent, the cost of this concession is hardly significant.

However, in order to avoid distrust, it is probably enough if there is a possibility for those who do not want to donate biological material for research purposes, to stay out of the bio-banks. From the point of view of the expected sum-total of happiness in the world there seems to be no problem with very broad kinds of consent, and even presumed consent, where it is made quite clear that, those who do not want to take part, may easily opt out. The use of broad consent and presumed consent, if possible, is in an obvious manner cost saving.

Should there be a right to withdraw biological material from the bio-bank, once it has been donated? We saw that from the point of view of the moral rights tradition, there is no such need. However, I think a good utilitarian argument could be given for this right. A person may donate to a biobank in good faith, only to notice that something nasty is being done with the aid of her biological material, such as cloning of human beings, to give a drastic example. The mere possibility of such cases provides a utilitarian rationale for a right to withdraw biological material. Otherwise, the trust in the system may go away.

What then of the establishment of a bio-bank, covering all citizens, and used for forensic purposes? Would the establishment of such a bio-bank mean a gain from to the point of view of the sum-total of happiness? To my own surprise I have come to think that would.

There is no way to avoid the establishment of some biobanks for forensic purposes. Such bio-banks exist in all industrially advanced societies. However, the standard procedure is to store material only from people who have been suspected or convicted of serious crimes. But in 
special circumstances even people not suspected of any crime may be forced to provide biological material for genetic diagnoses; this happens in relation to insurance issues, paternity conflicts, and in many other situations. This means that some people are as a matter of fact forced to give up their genetic integrity while others are allowed keep theirs. This is not fair. If everyone is required to store material in a forensic bio-bank, there should at least be no complaints from the point of view of fairness.

Does fairness play any role in a utilitarian calculus? It does, indirectly, since people have a concern for fairness.

Furthermore, if a forensic bio-bank would be established, covering every citizen, this would be a very strong resource in police work. It would render it more likely that those who are guilty of crime really get caught and it would render it more likely that those who are innocent don't.

Would such a bio-bank be cost effective? I leave that question open, but it seems to me that, it might very well be cost-effective, if it were established in a piecemeal manner, where samples were taken consecutively from infants. Then it would not be very expensive to establish it. ${ }^{9}$ And the benefits from it are rather obvious. It would be impossible to get a way with certain crimes, the risk of being accused and convicted of crimes for which you are not responsible would be reduced, and it is likely that it would affect in a positive manner the rate of crime in general.

What is a utilitarian to say of the use of spare genetic material? There is no denying that the possibility of the use of spare genetic material creates much pain among many people. It would be much better if such a practice could be rendered impossible. However, it is extremely difficult to think of an effective legal system, which could render such use, if not impossible, so at least very rare. This is really a problem for further discussion, but my conjecture is that such use of genetic material is something with which we will have to try to live-as happily as possible. This may render a lot of legislative work necessary. Perhaps we will have to ban the system of private health insurance all together and rely exclusively on a publicly financed system of health care, in order to avoid genetic discrimination. But this is beyond the scope of this short article.

\section{No overlapping consensus can be found}

We see that different moral outlooks give rise to different practical conclusions in many problems to do with biobanks. What are we to make of this diversity of views?

\footnotetext{
9 In Sweden the PKU register is an example of this kind of storing of genetic material. The word 'register', however, is a misnomer. The PKU register is a collection of blood samples from all infants; a forensic register used only for identification of individuals could be kept on a computer (only) and would hence be much cheaper.
}

First of all, I submit, we should reject the ethics of honour, according to which the individual is entitled to control his public picture. This idea may seem nice, when formulated like this, but once we realise that this view flies in the face of sound ideas about free speech, we should give it up. Here we should think more like Americans than like Continental Europeans-provided that Whitman's empirical speculations about the differences are correct. There is no possibility to argue this case in the present context. I just take this for granted and set this view to one side. I do so, furthermore, with the note that, should my rejection of this tradition be merely an idiosyncrasy on my part, this does not affect the main thesis of the article. On the contrary, if this tradition were taken seriously, it would be even more obvious that there is no possibility of arriving at any overlapping consensus on the matter here discussed.

We also saw that a defence of the right to privacy based on the idea that autonomy has value in itself was a nonstarter, at least in a discussion of bio-banks. We get such a weak notion out of this idea that it grants no protection whatever for donors of biological material to bio-banks. So I set this view to one side as well.

We are then left with the libertarian moral rights view and utilitarianism. They give both attractive pieces of advice, it seems to me, which are relevant to the questions posed here. To some small extent they converge, i.e. we reach an overlapping consensus. However, in important respects they give conflicting verdicts.

Let us first consider the consensus. There is consensus that biological material should not be stored in bio-banks without consent from the donors. We may perhaps also add that, while the moral rights view finds no problem with a system where spare genetic material is used for analysis, this is also accepted by utilitarianism-but only because there seems to be no way to avoid it!

Let us then turn to the points where they disagree.

The utilitarian claims that there should be a right for donors to withdraw material from the bio-bank if they feel that it is being used for purposes they do not like or, just because they have changed their mind. The moral rights theorist disagrees. Unless such a right to withdraw biological material was negotiated in the first place, it does not exist.

According to the moral rights view the consent form can be constructed in an inclusive manner (and here the utilitarian agrees), but, according to the moral rights view, there is no room for presumed consent (and here the utilitarian disagrees). According to the utilitarian we ought to create a bio-bank, to which everyone has to contribute, used exclusively for forensic purposes. At least this is what the utilitarian would claim, could such an initiative be shown to be cost-effective. The moral rights theorist strongly disagrees and disagrees on a principled basis. Such 
a system would violate basic rights, and it should be avoided, even if it turned out to be a cost-effective method of detecting and preventing criminal behaviour.

Given such disagreements, between ideas supported by cleaver contemporary as well as historical thinkers, what are the politicians to do?

\section{Conclusion}

I many situations, in liberal democracies, it is possible to find solutions to practical problems since there exist an overlapping consensus in the field. We may all agree, for example, and most importantly, that political decisions should be taken in a democratic manner. Well, even if some disagree, and claim that democracy means that the majority exercises a dictatorship over the minority, defending their disagreement with a reference to a libertarian theory of rights, we can just tell them that this is how we, the rest of us, want to arrange affairs. If they do not like this, they are free to move somewhere else. And it is not a valid complaint, on their part, that there is no place for them to go. The crucial thing is that we grant them a right to exit. On their favoured ethical view, it is their problem, not ours, to find a place for their political experiment.
There are exceptions to the rule that we can find an overlapping consensus when dealing with practical political matters, however. Famous such examples concern abortion, euthanasia, and the use of animals for food and medical experiments. If my argument in this article is sound, we have to count problems to do with bio-banking in the same contested category.

How can we deal with problems where no overlapping consensus can be found? There seems to be no other way of handling them than to settle the disputed questions through standard democratic procedures. The majority has its way. In the process, various different philosophical arguments can be pondered, of course, but if no overlapping consensus exists, the issues cannot be solved with reference to principles to which all can agree. And yet, since the problems are practical, we need to find solutions to them. However, when we solve them, we should realise that we are bound to end up with solutions that some people, for strong and principled reasons, feel are immoral. It may even be the case - as a matter of fact, it often is - that the result of the democratic political process is a compromise. Then it may well be the case that we have to live with laws for which there exists no plausible rationale. This is the necessary price we have to pay for living in a well-ordered society at all. ${ }^{10}$

\footnotetext{
${ }^{10}$ I write more about this general problem in 'Why No Compromise is Possible', Metaphilosophy, Vol. 38, pp. 330-343, 2007, reprinted in Lori Gruen, Laura Grabel, and Peter Singer (eds), Stem Cell Research: The Ethical Issues (Oxford: Blackwell, 2007).
} 